International Journal Of Mechanical Engineering And Information Technology

An Official Publication of IGM Publication

\title{
Investigation of Tribological Properties and Optimal Coating Material Selection for AISI 4140 Using TOPSIS and Taguchi Method
}

\author{
Authors \\ Joshi Gaurav Rajendra ${ }^{1}$, Prof Bhamre V.G. ${ }^{2}$ \\ ${ }^{1}$ PG Student SND COE \&RC, Yeola \\ ${ }^{2}$ Head Mechanical Engineering Department, SND COE \& RC Yeola \\ Email-gaurav.joshi307@gmail.com, bhamrevijay@gmail.com
}

\begin{abstract}
-
Depositions of surface coating materials is one of the important approaches in improving friction and wear properties of the surface, there is a growing demand for low friction coatings like TiN, TiAlN \& WCC that allow contacting surfaces to rub against with reduced friction and wear. Selection of different types of Nitriding process and coatings used on AISI 4140 steel to improve tribological properties by Multi Criteria Decision Making methods (MCDM) .The MCDM method used for selection namely TOPSIS (technique for order performance by similarity to ideal solution). Analytical hierarchy process (AHP) is used to find out weightage for the material criteria's like young's modulus(E), Hardness $(H), H / E, H^{3} / E^{2}$ and critical load for adhesion of coating for AISI 4140 steel. Each property is measured according appropriate standard. Selected AISI 4140 steel is optimized for tribological test settings using the grey relational analysis method. Taguchi method is implemented for experimental design which gives nine experimental runs based on orthogonal array. Coefficient of friction (COF) and wear is measured for nine different test on Pin on disc Tribometer. The optimal setting is selected and confirmation test is performed which gives clear indication of best material as well as optimum operating condition for AISI 4140 steel.

Keywords-COF, Pin on Disc, Taguchi, TOPSIS, Wear.
\end{abstract}

\section{INTRODUCTION}

The machining industry is constantly seeking ways to enhance performance (metal removal rate) and reduce cost of the manufactured parts. One way to enhance the machining performance is to utilize high speed machining. One of the problems associated with high speed machining is the high tool wear, leading to reduction in tool life. When the normal load and the sliding speed increased, the friction coefficient in air increased from 0.65 to 0.72 , whereas decreased from 0.58 to 0.36 in water and 0.20 to 0.08 in oil ${ }^{[1]}$. The wear resistant and thermally stable oxides formed by the tribo-chemical reactions of chromium and aluminum protected the $\mathrm{AlCrN}$ coating against wear admirably ${ }^{[3]}$. The results showed that the AlCrN coating exhibited higher hardness, but lower wear resistance as compared to the $\mathrm{CrN}$ coating. The AlCrN coating formed by $\mathrm{CrN}$ alloying with aluminum would show significantly improvement in high temperature oxidation resistance but not necessarily in wear resistance under the condition of ambient temperature ${ }^{[4]}$. The superiority of the AlTiN coating is confirmed by wear rates estimations ${ }^{[5]}$. Plasma nitriding has been carried-out to enhance surface related properties of steel components. The hardened case in these components comprise of a compound (white) layer on top followed by a diffusion zone underneath it. The increase in hardness and strength at the surface, yield improvement in fatigue life. However, increase in thickness of the compound layer beyond a certain critical reduces the fatigue life of the base material ${ }^{[7] .} \mathrm{CrN}$ coating gives better result against wear under dry and lubricated condition. AlCrN coating showed 
significant improvement in wear debris removal efficiency and load-carrying capacity as compared to the $\mathrm{CrN}$ coating when sliding against Si3N4 ball. The CrN coating exhibited higher wear resistance than the $\mathrm{AlCrN}$ coating under normal wear conditions. However, the $\mathrm{CrN}$ coating suffered severe concentrated wear under high normal load conditions, which was characterized by a combination wear mechanisms of delamination, abrasive and oxidative wear ${ }^{[10]}$.

Higher cutting temperature can also enhance the chemical reactivity between tool and certain work piece materials such as Titanium (Ti). This can lead to higher chemical wear thereby further reducing the tool life. Lower tool life leads to frequent tool changes resulting in increased machine down time. This in turn reduces the overall productivity. Hence, it is essential to minimize the tool wear \& tear and increase the life. This is possible by controlling the cutting temperature, time of cutting, using cutting oils etc. Conventionally the cutting temperature is lowered by the use of metal-cutting fluids (coolants). One of the alternatives to satisfy the demand for cost effective machining with reduced ecological impact is to employ high speed and/or dry machining technique. However, dry machining concept is still in its infancy and until it becomes a reality we must look for alternatives that will help us find ways to protect the tool from higher cutting temperature. This can be achieved through the exploitation of advanced surface coatings on cutting tools. Hard wear resistant coatings such as TiN, TiAlN \& WCC etc. provide overall improved tool life and better machining performance.

Due to the economic and environmental/ ecological costs, as well as health hazards, associated with conventional flooding of metal working fluids, or cutting fluids (CFs), in metal machining considerable research has been undertaken over the last decade to advance dry machining. In parallel, Minimal Quantity of Lubricant (MQL) application, or near-dry machining, a technique in which minute quantities of lubricant are sprayed near the cutting zone, has been investigated as an environmentally friendly and economically beneficial, hence sustainable, alternative to flooding of CFs under conditions where dry machining is not feasible.

Large number of materials has stimulated intense research in the field of material selection. Various quantitative decision making approaches are employed to select hard coating material selection. Technique for order preference by similarity to ideal solution (TOPSIS) is used for ranking these materials ${ }^{[17] .}$ The TOPSIS method determines a solution with the shortest distance to the ideal solution and the greatest distance from the negative-ideal solution, but it does not consider the relative importance of these distances ${ }^{[18]}$. In the present study, three different types of material selection problems are examined. A validation and consistency test of preference selection index method is performed in present work by comparing results of PSI method with published results of graph theory and matrix approach (GTMA), and technique for order preference by similarity to ideal solution (TOPSIS) method, respectively ${ }^{[20]}$. An attempt has been made to select the soft and hard magnetic materials using Multiple Attribute Decision Making (MADM) approach. VlseKriterijumska Optimizacija I Kompromisno Resenje (VIKOR) and Technique for order preference by similarity to ideal solution (TOPSIS) methods (MADM techniques) are employed to evaluate the relative ranking of these materials understudy ${ }^{[25]}$.

\section{PROBLEM DEFINITION}

\section{A. Problem Statement}

Investigation of Tribological Properties and Optimal Coating Material Selection for AISI 4140 Using TOPSIS and Taguchi Method.

The testing is done by considering following points;

1. Tribological study of various low friction coatings (TiN, TiAlN \& WCC)

2. To observe friction behavior of (TiN, TiAlN \& WCC) material. 
3. To observe wear of (TiN, TiAlN \& WCC) material under different varying condition.

\section{B. Objectives of The Present Work}

1. To determine the wear behavior of the selected materials and the effect of sliding speed, load and sliding distance.

2. To find the relationship between coefficient of friction, sliding distance and wear.

3. To find the effect of coating on wear rate and coefficient of friction.

4. To develop regression model to find out the mathematical relationship between Loads, Speed, sliding distance and amount of wear for all materials.

5. To conduct confirmation tests to check the efficiency of developed model.

6. To compare the main interaction, contour, 3D surface plot for all the materials.

7. Selection of Suitable coating from above using TOPSIS method.

\section{Proposed Methodology}

1. Literature review.

2. Selection of material for experiment.

3. Study of selected material and its composites.

4. Preparation of material for testing.

5. Use of 'Design Expert' and 'Minitab'.

6. Carry out Mechanical Metallography Test.

7. Carry out Testing using Pin-on-Disc machine.

8. Analysis using 'Design Expert 7' and 'Minitab'.

9. Selection of Suitable coating using TOPSIS method.

10. Report completion and other activities.

\section{Resources Required}

I. Hardware Required:

\section{A. Tribological Test}

1. Friction and Wear Monitor.

B. Mechanical Test

1. Metallography Test

II. Software Required:

A. Design Expert 7,
B. Minitab,

C. MS Excel.

\section{E. Application of Composite Material}

1. Aluminum alloy are one of the most attractive materials in transport vehicle application.

2. Enhancing the wear resistance of cutting tools, punches and several metal forming components.

3. Multilayered coatings improves the performance of material and also improves its fatigue life.

4. Nitriding helps to increase hardness of material and fatigue life of material.

5. The Ti-Based coatings have been widely used in the cutting tool industry due to their high hardness ans increased tool life.

\section{BASCIS OF COATINGS, DOE AND OPTIMIZATION}

\section{A. Basics of Coating}

Surface engineering, including surface treatments and coatings, is one of the most effective and flexible solutions for Tribological problems. Coatings change Tribological systems by inducing residual compressive stresses, decreasing the friction coefficient, increasing the surface hardness, altering the surface chemistry, changing the surface roughness. So, they improve the wear resistance of surfaces and extend the lifetime of relevant components. During last several decades, numerous coatings and deposition methods have been successfully developed and used to reduce friction or/and to protect surfaces from damage in mechanical systems.

The increasing use of coatings in Tribological applications is mainly based on the following reasons:

1. More and more scientists recognize that the surface is the most important part in many engineering components, and most failures have a relationship with the properties of the surface area.

2. Many other functionally important properties depend on the surface area, such 
as electronic, magnetic, optical, biocompatible characteristics.

Higher and higher performance is required for mechanical components and tools, which cannot be realized just by selecting materials or improving structures. The use of coatings can improve the performance of surface regions for friction reduction, wear resistance, corrosion resistance and other functionally attributes; at the same time, the substrate remains its original properties, responsible for the strength and toughness.

\section{B. Coating Types}

Since the successful application of coatings on, there are a huge variety of available coatings applied in tribological applications. In literature, coatings are commonly classified as soft coatings and hard coatings according to the hardness lower or higher than 10 GPA, because the hardness is generally looked as the most important parameter for the tribological response of a coating system. Soft coatings, such as polymers, soft metals, some carbon-based compositions and lamellar solids, are usually used to reduce friction, while hard coatings, such as oxides, carbides, nitrides, borides, and some carbon-based compositions, are believed with a good wear resistance, especially the ultra-hard coatings with an excellent abrasion resistance. Sometimes, coatings are also classified by thickness, as thin coatings and thick coatings. For thin coatings, the substrate will carry a large part of the load; therefore, the tribological response of coating systems depends on the properties of interface and substrate. When a coating is thick enough, it will support the whole load and work like a bulk material. After several decades of development, structures of tribological coatings go through an enormous change, from simple single to multi-layer, to gradient and to advanced adaptive coatings, as shown in Figure 1.

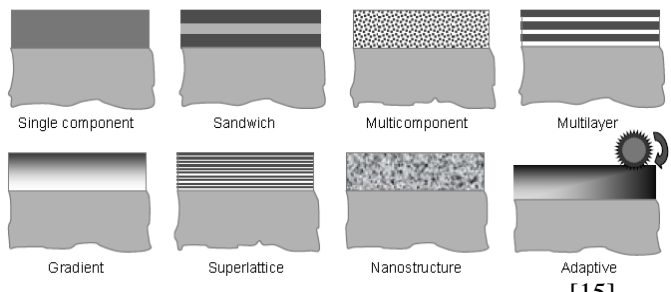

Fig. 1. Structures of Coatings ${ }^{[15]}$

The developments and new trends of tribological and solid lubricant coatings, and grouped the development of coating structure as four generations: single component coatings; multilayer and multicomponent coatings; gradient, super lattice and nanostructure coatings; smart coatings. The advantages of combining several structures and compositions within one coating include achievement of various individual physical properties, reduction of the mismatch in mechanical and chemical properties between the substrate and the coating, control of the residual stress within the coatings, the ability to stop cracks during operation under severe conditions, the adaptability with the change of operating conditions, and enhancement of hardness and/or toughness.

\section{Design of Experiment and Regression Analysis}

A brief introduction is given to the various tools and techniques, regression analysis based on statistical design of experiments used to model the wear equations.

\section{Design of Experiment}

It is methodology based on statistics and other discipline for arriving at an efficient and effective planning of experiments with a view to obtain valid conclusion from the analysis of experimental data. Design of experiments determines the pattern of observations to be made with a minimum of experimental efforts. To be specific Design of experiments (DOE) offers a systematic approach to study the effects of multiple variables / factors on products / process performance by providing a structural set of analysis in a design matrix. More specifically, the use of orthogonal Arrays (OA) for DOE provides an efficient and effective method for determining the most 
significant factors and interactions in a given design problem.

\subsection{Three Basic Principles of DOE \\ 1.1.1 Randomization}

You can re-randomize the run order of the experiments. You may want to do this if you do not like the current randomization (perhaps replicates were randomly placed together) or if you have added or deleted any runs. When you randomize, you will have the choice of randomizing a single block, or the entire experiment.

1. Sort by Run Order: This will re-order the design in the randomized run order. The initial run order is a completely random ordering of the experiments that should be followed when running the trials.

2. Sort by Standard Order: This will re-order the runs using the conventional standard ordering. This ordering remains the same every time a specific design is built. Most textbooks follow this order.

3. Re-Order as currently displayed: This will re-number the runs to reflect their current order. Use this feature if you have created a new experimental order by sorting the design on a given factor column. By not randomizing the experiments, you introduce some potential bias from lurking variables. Check the Design Evaluation for the alias structure.

\subsubsection{Replication}

By specifying the number of replicates you tell Design-Expert how many times each design point (set of experimental conditions) should be run. The default is 1 replicate, which means that each design point will be run once. If you ask for 2 replicates, then each experimental condition will be repeated. Repeats provide you with the ability to compute estimates of pure error.

It is important to remember the difference between replicates and repeated measurements. A true replicate of a design point is the result of physically re-creating all the conditions for that experiment. This will give a more accurate estimate of the overall process error.

If you take several samples out of the same run, this is considered a repeated measurement. The variation observed in the responses of repeated measurements does not reflect the complete process error, but only the sample to sample or measurement variation. If you treat repeated measurements as replicates, the pure error estimate will be too small. If you have a lot of sample to sample variability, you may want to take several samples, enter the raw data into a spread sheet, and then calculate the average measurement from the samples. Enter the average as the response for each run.

An additional comment about replicating fractional factorial designs: If you are starting with a fractional factorial design it may make more sense to move to a larger fractional factorial that contains more unique combinations than to add replicates. The effects are estimated by averaging all of the runs, so by increasing the number of unique runs, you are both increasing the power of the design to detect effects and increasing the number of terms that can be independently estimated. By adding replicates you are increasing the power, but not gaining any additional information.

\subsubsection{Blocking}

Blocking is a technique used to remove the expected variation caused by some change during the course of the experiment. For example, you may need to use two different raw material batches to complete the experiment, or the experiment may take place over the course of several shifts or days. Design-Expert provides various options for blocking, depending on how many runs you choose to perform. The default of 1 block really means "no blocking."

For example, in experiments with 16 runs, you may choose to carry out the experiment in 2 or 4 blocks. Two blocks might be helpful if, for some reason, you must do half the runs on one day and the other half the next day. In this case, day to day 
variation may be removed from the analysis by blocking.

When you choose to block your design, one or more effects will no longer be estimable. You can look at the alias structure to see which effects have been "lost to blocks." This is especially important when you have 4 or more blocks. In certain cases, a two-factor interaction may be lost and so then you will want to make sure that the interaction is not one that you are interested in.

Another note about blocking - it is assumed that the block variable does not interact with the factors. The effect must only be a linear shift, and not be dependent on the level of one or more of the factors under study.

\section{Introduction to Taguchi Method}

A full factorial design will identify all possible combinations for a given set of factors. If an experiment consist of $m$ number of factors \& each factor at level, then number of trail possible, (Treatment Combination) $=\mathrm{X}^{\mathrm{m}}$

\subsection{Background}

As the number of factors considered at multilevels increases, it becomes increasingly difficult to conduct the experiment with all treatment combinations. To reduce the number of experiments to practical level, only a small set from all the possibilities is selected. The method of selecting a limited number of experiments, which produces the most information, is known as a practical fractional experiment, but there are no general guidelines for fractional experiments that cover many applications. This method uses a special set of arrays called orthogonal arrays. These standard arrays stipulate the way of conducting the minimal number of experiments, which could give the full information of all the factors that affect the performance parameter. The crux of the orthogonal arrays method lies in choosing the level combinations of the input design variables for each experiment.

\subsection{Typical Orthogonal Array (OA)}

While there are many standard orthogonal arrays available, each of the arrays is meant for a specific number of independent design variables and levels. Standard notation for orthogonal Arrays is,

$$
\mathrm{L}_{\mathrm{n}}\left(\mathrm{X}^{\mathrm{m}}\right)
$$

Where,

$\mathrm{n}=$ Number of experiments to be conducted

$\mathrm{X}=$ Number of levels

$\mathrm{m}=$ Number of factors

Common Orthogonal Arrays are as follows

(2- Level arrays)--- $\mathrm{L}_{4}\left(2^{3}\right), \mathrm{L}_{8}\left(2^{7}\right), \mathrm{L}_{12}\left(2^{11}\right), \mathrm{L}_{16}$ $\left(2^{15}\right), \mathrm{L}_{32}\left(2^{31}\right), \mathrm{L}_{64}\left(2^{63}\right)$ etc.

(3- Level arrays)--- $\mathrm{L}_{9}\left(3^{4}\right), \mathrm{L}_{18}\left(2^{1} * 3^{7}\right), \mathrm{L}_{27}\left(3^{13}\right)$, $\mathrm{L}_{54}\left(2^{1} * 3^{25}\right), \mathrm{L}_{81}\left(3^{40}\right)$ etc.

(4-Level arrays)--- $\mathrm{L}_{16}\left(4^{5}\right), \mathrm{L}_{32}\left(2^{1} * 4^{9}\right)$ etc.

For example, if one wants to conduct an experiment to understand the influence of 4 different independent variables with each variable having 3 set values (levels), then an $\mathrm{L}_{9}$ orthogonal array might be the right choice. The $\mathrm{L}_{9} \mathrm{OA}$ is meant for understanding the effect of 4 independent factors each having 3 factor level values. This array assumes that there is no interaction between any two factors, while in many cases, no interaction model assumption is valid, and there are some cases where there is a clear evidence of interaction.

\subsection{Properties of an Orthogonal Array (OA)}

Orthogonal array has following properties that reduce number of experiments to be conducted.

1. First row has all 1's. There is no row that has all 2's or all 3's.

2. The columns of the array are orthogonal or balanced. This means that the level settings appear an equal number of times. The columns are also balanced between any two. This means that level combination exist in equal numbers and is unique.

3. Effect of factor A can be separated from the effects of other factors B, C, D, etc. and vice-versa.

4. Because of the balancing property, total number of experiments shall be multiple of $2 \& 3$. 
Table 1 Layout of $\mathrm{L}_{9}\left(3^{4}\right)$ Orthogonal Array

\begin{tabular}{|l|l|l|l|l|}
\hline $\begin{array}{l}\text { Trial } \\
\text { No. }\end{array}$ & Factor A & Factor B & Factor C & $\begin{array}{l}\text { Response } \\
\text { Y }\end{array}$ \\
\hline 1 & 1 & 1 & 1 & Y1 \\
\hline 2 & 1 & 2 & 2 & Y2 \\
\hline 3 & 1 & 3 & 3 & Y3 \\
\hline 4 & 2 & 1 & 2 & Y4 \\
\hline 5 & 2 & 2 & 3 & Y5 \\
\hline 6 & 2 & 3 & 1 & Y6 \\
\hline 7 & 3 & 1 & 3 & Y7 \\
\hline 8 & 3 & 2 & 1 & Y8 \\
\hline 9 & 3 & 3 & 2 & Y9 \\
\hline
\end{tabular}

\section{Experimental Design Procedure: An Outline}

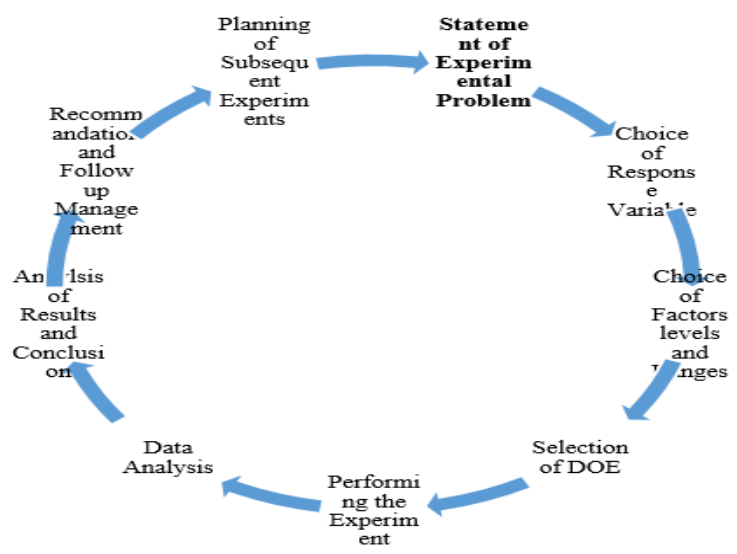

Fig. 2. Outline of Recommended Procedure for an Experimental Design

\section{E. TOPSIS Method}

TOPSIS is generally used to find preferential ranking of all alternate by using output response of each criteria and to convert multi criteria system into preferential index. The value which is close from ideal solution, according benefit and cost situation of all criteria will be used. The TOPSIS consists of following steps

a. Normalization of decision matrix is performed by using Eq. (1).

$$
\begin{gathered}
n_{i j}=\frac{x_{i j}}{\sqrt{\sum_{i=1}^{m} x_{i j}^{2}}}, i=1,2, \ldots, m ; j \\
=1,2, \ldots . n
\end{gathered}
$$

b. Weightage normalization of the normalized values obtain from $\mathrm{Eq}$ (1) is carried by multiplying weightage factors of each criteria to normalized values of each criteria which gives us weighted and normalized decision matrix
(2)

$$
V_{i j}=w_{j} n_{i j}
$$

c. Determine positive and negative ideal solution (PIS) and (NIS) for weighted normalized decision matrix. These values are denoted by Eq. (3) and Eq. (4).

$$
\begin{aligned}
& A^{*}=\left\{V_{1}^{*}, V_{2}^{*}, \ldots, V_{i}^{*}\right\} \\
& =\left\{\begin{array}{cc}
\left(\max V_{i j} \mid i \in I^{\prime}\right) & \left(\min V_{i j} \mid i \in I^{\prime \prime}\right) \\
j & j
\end{array}\right\} \\
& A^{-}=\left\{V_{1}^{-}, V_{2}^{-}, \ldots, V_{i}^{-}\right\}= \\
& \left\{\begin{array}{cc}
\left(\min V_{i j} \mid i \in I^{\prime}\right) & \left(\max V_{i j} \mid i \in I^{\prime \prime}\right) \\
j
\end{array}\right\}
\end{aligned}
$$

Where $I^{\prime}$ is associated with benefit criteria, and $I^{\prime \prime}$ with cost criteria.

d. Calculate separation measures. The variation of each alternative from PIS $\left(S_{j}^{*}\right)$ and from NIS $\left(S_{j}^{-}\right)$ is calculated as root mean square variation of PIS and NIS

$$
\begin{gathered}
S_{j}^{*}=\sqrt{\sum_{i=1}^{n}\left(V_{i j}-V^{*}\right)^{2}, j} \\
=1,2, \ldots \ldots, m, \\
S_{j}^{-}=\sqrt{\sum_{i=1}^{n}\left(V_{i j}-V^{-}\right)^{2}}, j \\
=1,2, \ldots, m,
\end{gathered}
$$

e. Calculate the relative closeness to ideal solution where $C_{j}$ index value lies between 0 and 1 .

$$
\begin{gathered}
C_{j}=\frac{D_{j}^{-}}{D_{j}^{*}-D_{j}^{-}} \quad, j \\
=1,2, \ldots \ldots m,
\end{gathered}
$$

Ranking should be done as per the descending values of $C_{j}$, Greater values means higher rating.

\section{EXPERIMENTATION}

\section{A. Pin on Disc Machine}

A schematic pin on disc tribometer as shown in fig.3 (a) and (b) is the standard equipment used to 
determine the sliding friction coefficient and wear resistance of surfaces. The tester consists of a stationary "pin" under an applied load in contact with a rotating disc. Either the pin or the disc can be wear- and friction-tested using the pin on disc tester. The pin is usually a sphere however it may be any geometry that simulates the actual application counter surface. A load cell attached to the pin on disc tester is used to measure the evolution of the friction coefficient with sliding distance and it was calibrated with the thickness gauge inserted between LVDT and support and error displayed was \pm 5 micron.
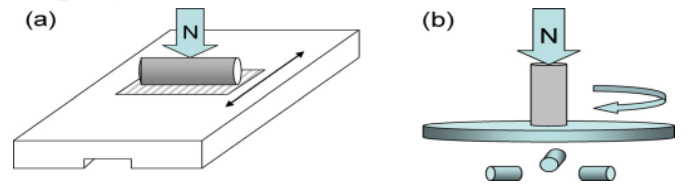

Fig. 3 .Schematic of pin-on-disk test. (a)

Reciprocating mode and (b) unidirectional (3button) mode ${ }^{[8]}$.

The typical pin specimen is cylindrical or spherical in shape. Cylindrical or spherical pin specimen diameter ranges from 2 to $10 \mathrm{~mm}$. The disk specimen diameter ranges from 30 to 100 $\mathrm{mm}$ and have a thickness in the range of 2 to 10 $\mathrm{mm}$.

The sample used in the experiment is a midcarbon low alloyed AISI 4140 improved steel. The substrate is first machined and then finished to a pin of dia. $6 \mathrm{~mm}$ and $30 \mathrm{~mm}$ length. Both ends of pin are finished with surface roughness of 0.8 micron using ASTM G99 04. The above specimens are nitrated at a temperature of $450^{\circ} \pm 50^{\circ}$ $\mathrm{C}$ and PVD coated with TiN, TiAlN and WCC with the thickness of 4 micron. The Disk is made up of EN 8 material having diameter $160 \mathrm{~mm}$ and thickness of $8 \mathrm{~mm}$ which was electroplated. The Pin on Disc specimens are shown in fig. 4 and 5

\section{Parameter Selection}

Coating selected:- TiN, TiAlN and WCC

Coating thickness: - 04 micron

Speed: - 500,750,100 rpm

\section{Specimen Preparation}

Mechanical metallography test:-Shamukha_lab, Near symbiosis institute, Ambad, Nashik
Specimen prepared - Sai engg, Ambad, Nashik Nitriding - Avdhoot heat treatment, W117, Ambad, Nashik

Coating - Balzer pvt. Ltd, E25, Bhosri MIDC, Pune.

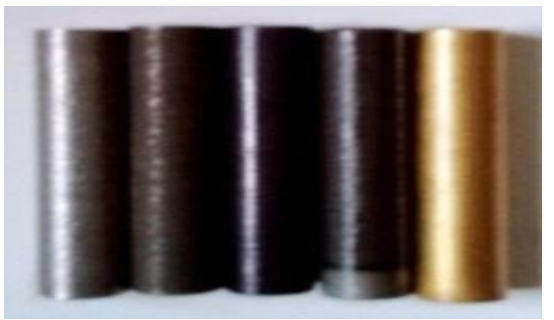

Fig. 4 (a) Wear and COF Test specimen of AISI 4140, (b) Nitrided AISI 4140, (c) Nitrided and TiAlN Coated AISI 4140, (d) Nitrided and WCC Coated AISI 4140, (e)Nitrided and TiN Coated AISI 4140

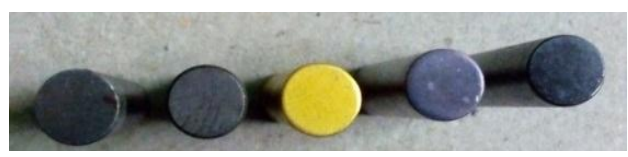

Fig. 5 (a) Wear and COF Test specimen of AISI 4140, (b) Nitrided AISI 4140, (c) Nitrided and TiN Coated AISI 4140, (d) Nitrided and TiAlN Coated AISI 4140, (e)Nitrided and WCC Coated AISI 4140

\section{RESULTS AND DISCUSSION}

\section{A. Wear}

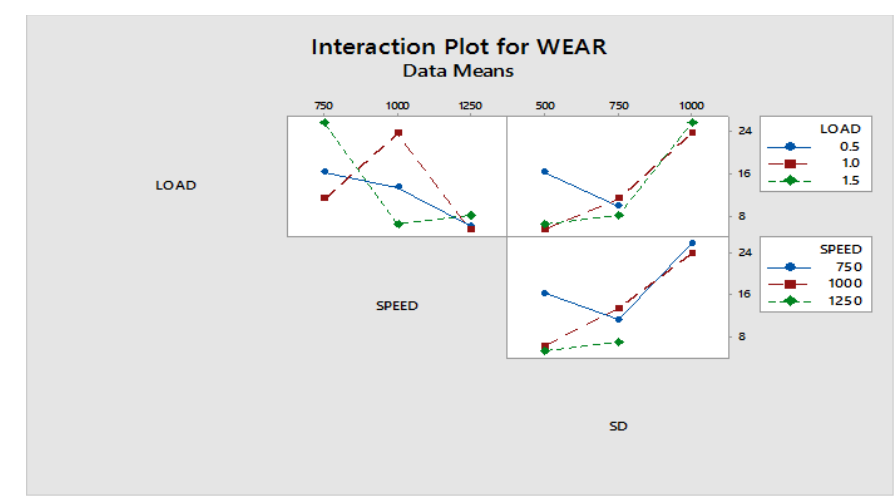

Fig. 6. Interaction plot for wear of TiN coating 


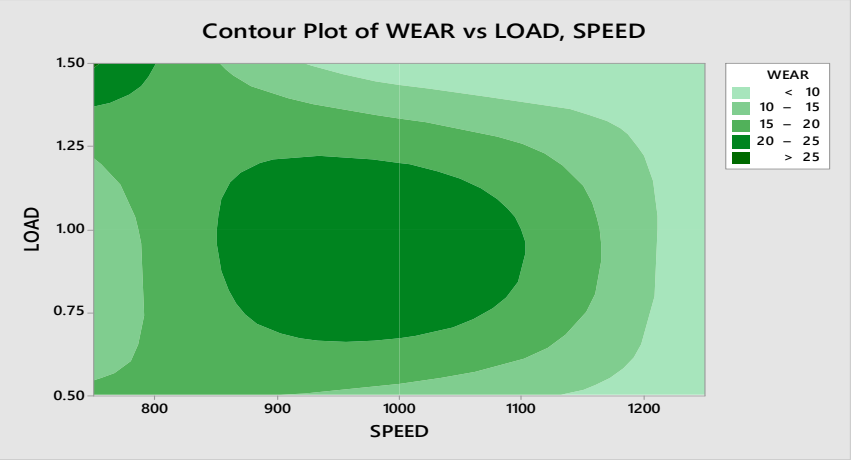

Fig. 7. Contour plot for wear of TiN coating

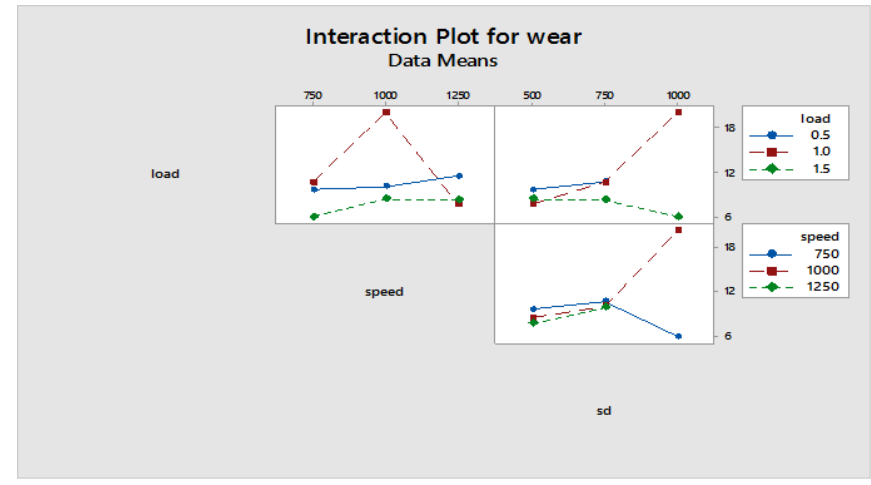

Fig. 8 Interaction plot for wear of TiAlN coating

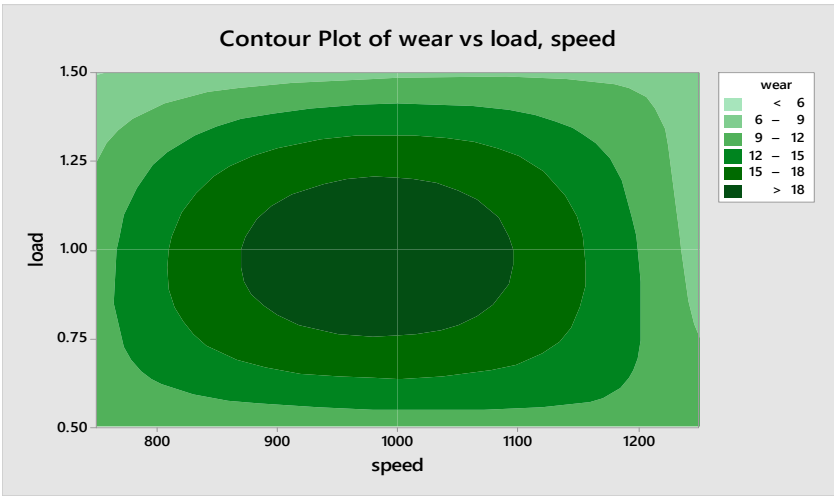

Fig. 9 Contour plot for wear of TiAlN coating

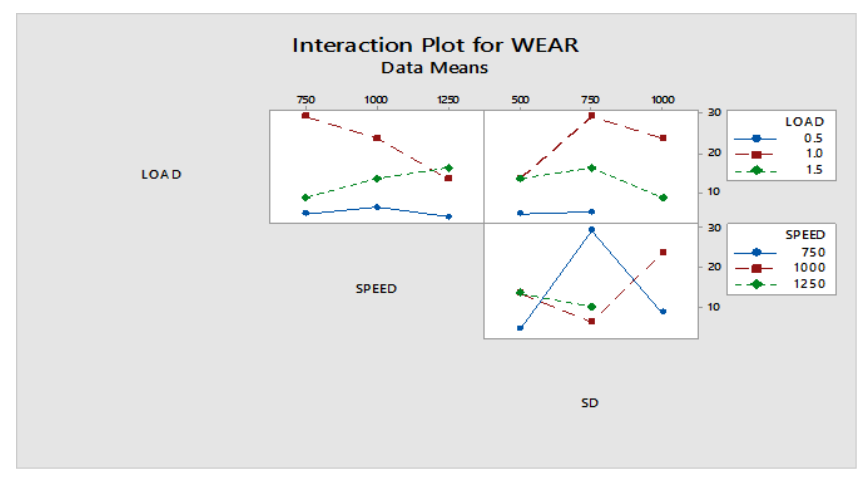

Fig.10 Interaction plot for wear of WCC coating

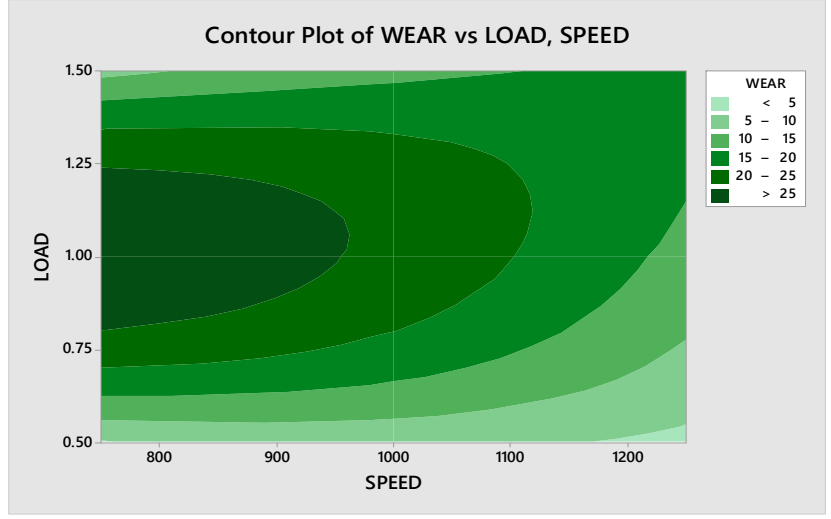

Fig. 11 Contour plot for wear of WCC coating

From the above fig.no $6 \& 7$, Wear test results it can be observed that when the specimen is nitrided and coated with TiN, its wear resistance increases. The lowest value of the wear observed is 10 micron. From the above fig.no $8 \& 9$, Wear test results it can be observed that when the specimen is nitrided and coated with TiAlN, its wear resistance increases. The lowest value of the wear observed is 06 micron. From the above fig.no $10 \& 11$, Wear test results it can be observed that when the specimen is nitrided and coated with WCC, its wear resistance increases. The lowest value of the wear observed is 03 micron. Hence the best suited material from the above various materials for wear are nitrided and TiAlN coated AISI 4140 steel.

\section{B. COF}

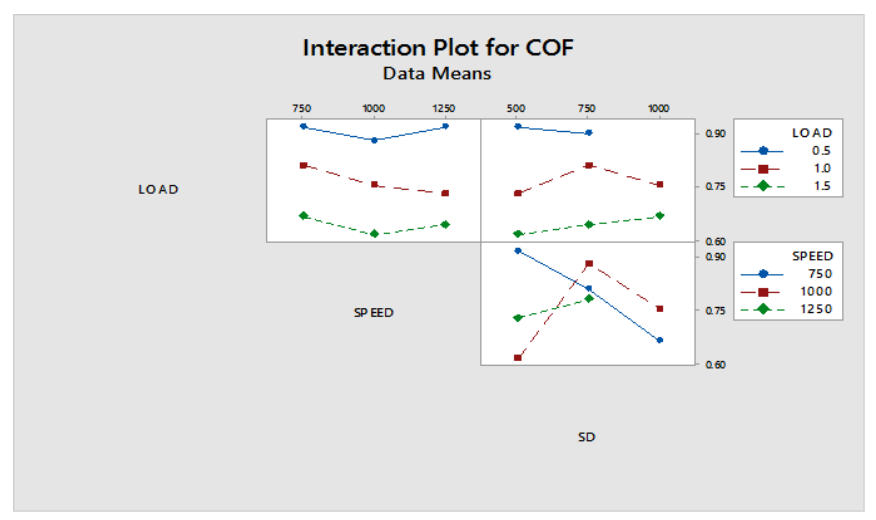

Fig. 12 Interaction plot for COF of TiN coating 


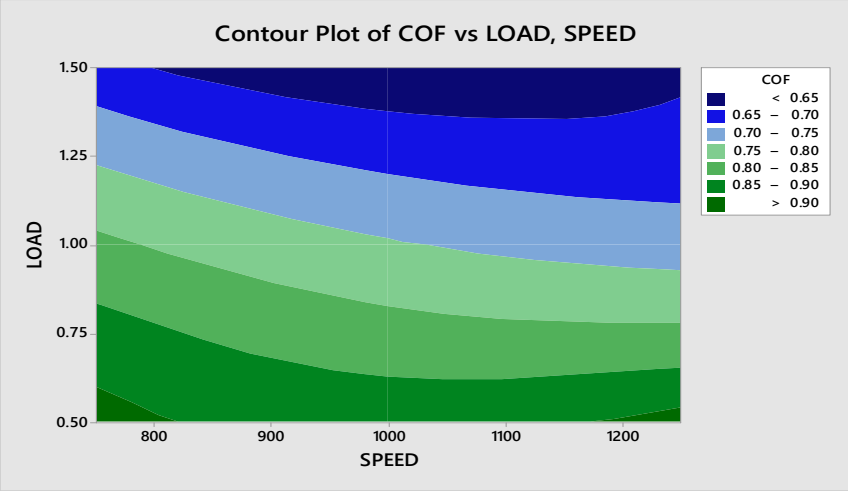

Fig. 13 Contour plot for $\mathrm{COF}$ of TiN coating

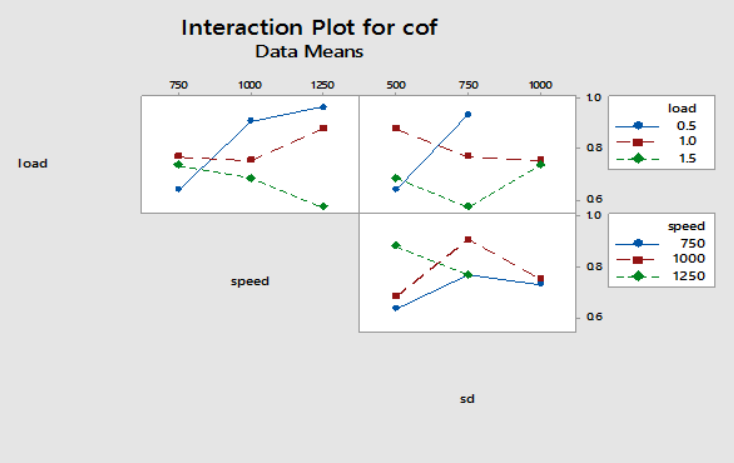

Fig. 14 Interaction plot for COF of TiAlN coating

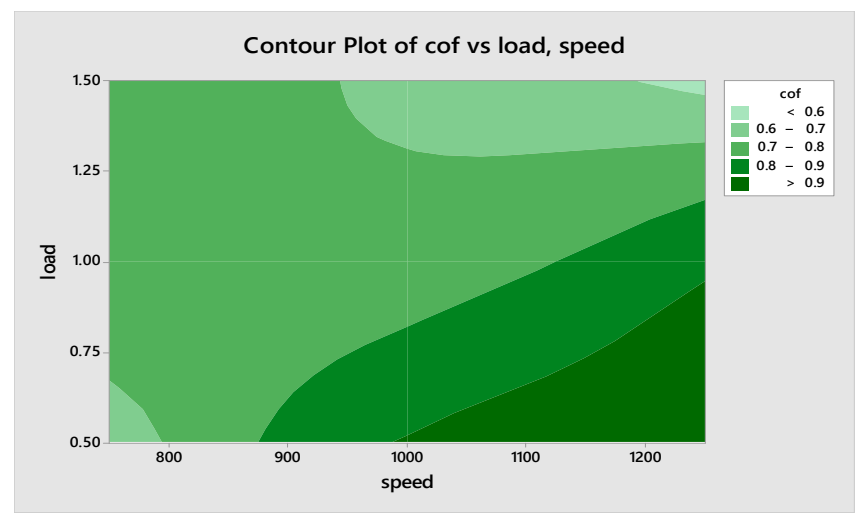

Fig. 15 Contour plot for COF of TiAlN coating

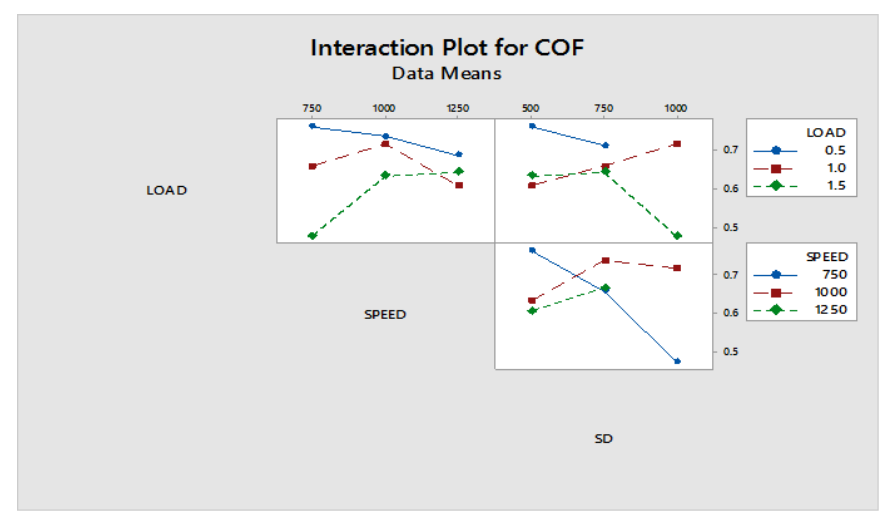

Fig. 16 Interaction plot for COF of WCC coating

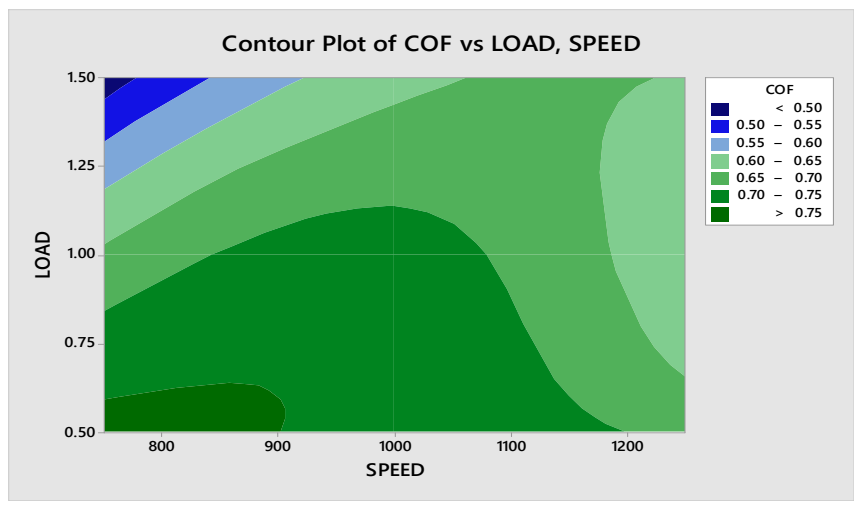

Fig. 17 Contour plot for COF of WCC coating From fig.no12\&13, Friction test results it can be concluded that when the specimen is nitrided and coated with TiN, its COF decreases which is desirable. The lowest valve observed for the $\mathrm{COF}$ is 0.675 . From fig.no $14 \& 15$, Friction test results it can be concluded that when the specimen is nitrided and coated with TiAlN, its COF decreases which is desirable. The lowest valve observed for the $\mathrm{COF}$ is 0.645 . From fig.no $16 \& 17$, Friction test results it can be concluded that when the specimen is nitrided and coated with WCC, its COF decreases which is desirable. The lowest valve observed for the COF is 0.25 .Hence the best suited material from the above various materials for $\mathrm{COF}$ are nitrided and WCC coated AISI 4140 steel.

\section{Optimization:}

In TOPSIS, According to steps given in a section (TOPSIS method theory)

1. Normalizing of decision matrix for each criteria is carried out by using Eq. (1),

2. Then weightage normalization is carried by using weightage obtain by criteria weighting method,

3. PIS and NIS is calculated according to the criteria of each alternative by using Eq. (3) (4),

4. Distance from PIS $\left(\boldsymbol{S}_{\boldsymbol{j}}^{*}\right)$ and NIS $\left(\boldsymbol{S}_{\boldsymbol{j}}^{-}\right)$of each criteria were represented by Eq.(5) (6),

5. Relative closeness to the ideal solution can be calculated by using Eq. (7),

6. Alternative with the highest $C_{j}$ gives the best rank. 
Table 2 shows all results with ranking. The best alternative as the coating material was found to be nitride and WCC coating, and then followed by nitride and TiAlN coating for AISI 4140 alloy steel.

\section{CONCLUSION}

Selection problem for Nitriding deposition and coatings of AISI 4140 steel solved based on their mechanical and tribological properties utilizing multi-criteria decision making methods. Weightage of each criteria for material selection is carried out through compromised weighting method which gives the most important criteria to be critical load. Nitride deposited and WCC coated AISI 4140 steel selected to be the best material .Nitride deposited and TiAlN coated AISI 4140 steel next best material.
Selected Nitride deposited and WCC coated material is tested to optimize operating condition for the AISI 4140 steel on "PIN ON DISC" Apparatus by Using Taguchi Method. Wear and coefficient of friction were the criteria's used for multi criteria optimization with help of grey relation method, The results shows the optimal operating settings for Nitride deposited and WCC coated AISI 4140 steel is A1B1C3(load $0.5 \mathrm{~kg}$, Sliding speed $750 \mathrm{rpm}$ and sliding distance $1 \mathrm{~km}$ )

Table 2 Observed Values of Wear And COF in Tribological Test

\begin{tabular}{|c|c|c|c|c|c|c|c|c|c|c|c|c|c|}
\hline \multirow{2}{*}{$\begin{array}{l}\text { Sr. } \\
\text { No }\end{array}$} & \multirow{2}{*}{$\begin{array}{l}\text { Load } \\
(\mathrm{kg})\end{array}$} & \multirow{2}{*}{$\begin{array}{l}\text { Speed } \\
(\mathrm{rpm})\end{array}$} & \multirow{2}{*}{$\begin{array}{l}\text { Sliding } \\
\text { Distance } \\
\text { (m) }\end{array}$} & \multicolumn{2}{|c|}{ AISI 4140 Steel } & \multicolumn{2}{|c|}{$\begin{array}{l}\text { AISI } 4140 \text { Steel } \\
\text { Nitrided } \\
\end{array}$} & \multicolumn{2}{|c|}{$\begin{array}{l}\text { AISI } 4140 \text { Steel } \\
\text { Nitrided TiN }\end{array}$} & \multicolumn{2}{|c|}{$\begin{array}{l}\text { AISI } 4140 \text { Steel } \\
\text { Nitrided TiAIN } \\
\end{array}$} & \multicolumn{2}{|c|}{$\begin{array}{l}\text { AISI } 4140 \text { Steel } \\
\text { Nitrided WCC }\end{array}$} \\
\hline & & & & $\begin{array}{l}\text { Wear } \\
\text { (micron) }\end{array}$ & COF & $\begin{array}{l}\text { Wear } \\
\text { (micron) }\end{array}$ & COF & $\begin{array}{l}\text { Wear } \\
\text { (micron) }\end{array}$ & COF & $\begin{array}{l}\text { Wear } \\
\text { (micron) }\end{array}$ & COF & $\begin{array}{l}\text { Wear } \\
\text { (micron) }\end{array}$ & COF \\
\hline 1 & 0.5 & 750 & 500 & 3.7737 & 0.8628 & 36.4631 & 0.9460 & 16.2588 & 0.9184 & 9.6082 & 0.6351 & 4.5566 & 0.7630 \\
\hline 2 & 0.5 & 1000 & 750 & 8.7924 & 0.9495 & 11.7897 & 0.9509 & 13.3488 & 0.8806 & 10.009 & 0.9081 & 6.2596 & 0.7370 \\
\hline 4 & 1 & 750 & 750 & 12.8560 & 0.8388 & 12.3112 & 0.7887 & 11.1861 & 0.8106 & 10.6339 & 0.7674 & 29.3594 & 0.6588 \\
\hline 5 & 1 & 1000 & 1000 & 11.3324 & 0.8396 & 26.6504 & 0.7495 & 23.6968 & 0.7550 & 20.1898 & 0.7540 & 23.6813 & 0.7166 \\
\hline 6 & 1 & 1250 & 500 & 5.0628 & 0.8347 & 7.4435 & 0.7916 & 5.2145 & 0.7296 & 7.6425 & 0.8808 & 13.4494 & 0.6069 \\
\hline 9 & 1.5 & 1250 & 750 & 18.7507 & 0.48195 & 12.8569 & 0.6833 & 7.8647 & 0.6429 & 8.1516 & 0.5684 & 16.2162 & 0.6442 \\
\hline
\end{tabular}

Table 3 Weighted And Normalized Decision Matrix With Ranking, $V_{i j}$

\begin{tabular}{|l|c|c|c|l|}
\hline SR NO & $\boldsymbol{S}_{\boldsymbol{j}}^{*}$ & $\boldsymbol{S}_{\boldsymbol{j}}^{-}$ & $\boldsymbol{C}_{\boldsymbol{j}}$ & RANK \\
\hline $\mathbf{1}$ & 0.3521 & 0.0000 & 0.0000 & 5 \\
\hline $\mathbf{2}$ & 0.3265 & 0.0232 & 0.0988 & 4 \\
\hline $\mathbf{3}$ & 0.1352 & 0.2652 & 0.5968 & 3 \\
\hline $\mathbf{4}$ & 0.0876 & 0.2917 & 0.8925 & 2 \\
\hline $\mathbf{5}$ & 0.0000 & 0.3652 & 1.0000 & 1 \\
\hline
\end{tabular}




\section{REFERENCES}

1. Fei Zhou, YuanWang, Feng Liu, Yuedong Meng, Zhendong Dai, "Friction and wear properties of duplex MAO/CrN coatings sliding against Si3N4 ceramic balls in air, water and oil" Wear 267 (2009) 15811588 .

2. Dheepa Srinivasan, Trupti. G. Kulkarni, K. Anand, "Thermal stability and hightemperature wear of $\mathrm{Ti}-\mathrm{TiN}$ and $\mathrm{TiN}-\mathrm{CrN}$ nanomultilayer coatings under self-mated conditions" Tribology International 40 (2007) 266-277

3. J.L. Mo, M.H. Zhu "'Sliding tribological behavior of $\mathrm{AlCrN}$ coating" Tribology International 41 (2008) 1161- 1168

4. J.L. Mo, M.H.Zhu, "Tribological oxidation behaviour of PVD hard coatings" Tribology International 42 (2009) 1758-1764

5. Yucel Birol "Sliding wear of $\mathrm{CrN}, \mathrm{AlCrN}$ and AlTiN coated AISI H13 hot work tool steels in aluminium extrusion" Tribology International 57 (2013) 101-106

6. M. Antonov, I. Hussainova, F. Sergejev, P. Kulu, A. Gregor, "Assessment of gradient and nanogradient PVD coatings behaviour under erosive, abrasive and impact wear conditions" Wear 267 (2009) 898-906

7. U. N. Puntambekar, G. S. Grewal, P. B. Joshi and P. Sampathkumaran " Effect of Plasma Nitriding Treatment on Fatigue Life of En-24 steel" International Journal of Innovative Research in Science,
Engineering and Vol. 2, Issue 8, August 2013

8. S.J. Shaffer, M.J. Rogers.“Tribological performance of various coatings in unlubricated sliding for use in small arms action components - A case study" Wear 263 (2007) 1281-1290

9. Fei Zhoua, Kangmin Chen, MeilingWang, Xiaojing $\mathrm{Xu}$, Hua Meng, Min Yua, Zhendong Daia "Friction and wear properties of $\mathrm{CrN}$ coatings sliding against Si3N4 balls in water and air" Wear 265 (2008) 1029-1037

10. J.L. Mo, M.H. Zhu, "Sliding tribological behaviors of PVD $\mathrm{CrN}$ and $\mathrm{AlCrN}$ coatings against Si3N4 ceramic and pure titanium" Wear 267 (2009) 874-881

11. V. Podgursky, R. Nisumaab, E. Adoberg, A. Surzhenkov, A. Sivitski , P.Kulu, "Comparative study of surface roughness and tribological behavior during runningin period of hard coatings deposited by lateral rotating cathode arc" Wear 268 (2010) 751-755

12. J.M. Fildes , S.J.Meyers , C.P.Mulligan , R.Kilaparti, "Evaluation of the wear and abrasion resistance of hard coatings by ball-on-three-disk test methods-A casestudy" Wear 302 (2013) 1040-1049

13. C. Lorenzo-Martin , O.Ajayi , A.Erdemir, G.R.Fenske , R.Wei, "Effect of microstructure and thickness on the friction and wear behavior of $\mathrm{CrN}$ coatings" Wear 302 (2013) 963-971

14. Xin Wang , Parick Y. Kwon, David Schrock, Dave(Dae-Wook)Kim "Friction coefficient and sliding wear ofAlTiN coating under various lubrication conditions" Wear304(2013)67-76

15. B. Warcholinski, A. Gilewicz "Tribological properties of $\mathrm{CrN}$, coatings" JOASSME VOLUME 37 ISSUE December 2009. 
16. L.A. Dobrzański ， M. Staszuk ， M. Pawlyta, W. Kwaśny , M. Pancielejko, "Characteristics of $\mathrm{Ti}(\mathrm{C}, \mathrm{N})$ and $(\mathrm{Ti}, \mathrm{Zr}) \mathrm{N}$ gradient PVD coatings deposited onto sintered tool materials" JOASSME VOLUME 31 ISSUE 2 December 2008.

17. Aditya Chauhan, Rahul Vaish "Hard coating material selection using multicriteria decision making" Materials and Design 44 (2013) 240-245.

18. Serafim Opricovic, Gwo-Hshiung Tzeng, "Compromise solution by MCDM methods:A comparative analysis of VIKOR and TOPSIS"

19. A.Baradeswaran A.Elayaperumal, R. Franklin Issac "A Statistical Analysis of Optimization of Wear Behaviour of AlA12O3 Composites Using Taguchi Technique," International Conference On DESIGN AND MANUFACTURING, IConDM 2013. Procedia Engineering 64 ( 2013 ) $973-982$

20. Kalpesh Maniya , M.G. Bhatt, “A selection of material using a novel type decision-making method:Preference selection index method Materials and Design 31 (2010) 1785-1789

21. Ali Jahan, Marjan Bahraminasab , K.L. Edwards, "A target-based normalization technique for materials selection" Materials and Design 35 (2012) 647-654

22. E.Manokaran, S.Subhashini, S.Senthilvel, Dr.R.Muruganandham,

Dr.K.Ravichandran , "Application of Multi Criteria Decision Making Tools and Validation with Optimization TechniqueCase Study usingTOPSIS, ANN \& SAW" IJMBS Vol. 1, Issue 3, September 2011 ISSN : 2330-9519 (Online) | ISSN : 22312463 (Print)

23. Aditya Chauhan, Rahul Vaish, "Hard coating material selection using multicriteria decision making" Materials and Design 44 (2013) 240-245.
24. N. Radhika, R. Subramanian, S. Venkat Prasat, "Tribological Behaviour of Aluminium/Alumina/Graphite Hybrid Metal Matrix Composite Using Taguchi's Techniques" Journal of Minerals \& Materials Characterization \& Engineering, Vol. 10, No.5, pp.427-443, 2011

25. Aditya Chauhan, Rahul Vaish, "Magnetic material selection using multiple attribute decision making approach" Materials and Design 36 (2012) 1-5.

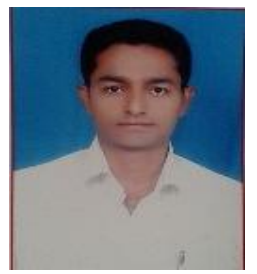

Gaurav R Joshi was born in Ahmednagar City, in 1988.He received the B.E. degree in mechanical engineering from the University of Pune, Maharashtra, in 2012 and pursuing ME Design degree in mechanical engineering from Pune University at SNDCOE\&RC, Yeola, Maharashtra. He attended national conferences on research methodology. 